\title{
Design e Cultura Popular - A Atuação do Laboratório de Design Solidário
}

\author{
Design and Popular Culture - The Performance of Solidarity Design Laboratory
}

\author{
Goya, Claudio Roberto y; doutor; Universidade Estadual Paulista "Júlio de Mesquita Fillho" \\ goyaclaudio@hotmail.com \\ Souza, Juliana Soares de; mestre; Universidade Federal de São Carlos \\ soares.s.juliana@gmail.com
}

\section{Resumo}

O presente artigo apresenta a trajetória do Projeto de Extensão Universitária Laboratório de Design Solidário, Labsol, do Departamento de Design da Faculdade de Arquitetura, Artes e Comunicação da Universidade Estadual Paulista Júlio de Mesquita Filho, no campus de Bauru. 0 Labsol atua na área do Design Social relacionando uma perspectiva que atua na relação entre o design e o artesanato, por meio do atendimento, numa relação dialógica, à comunidades produtoras de artesanato, tendo como objetivos a geração de trabalho e renda, desenvolvendo produtos com o intuito de resgatar identidade cultural dos grupos atendidos, valorizando a cultura local e os diversos modos de fazer. O Labsol se organiza em 2007 por iniciativa do professor coordenador e um grupo de alunos voluntários e nos anos que se seguem adota pressupostos teóricos que abarcam o Ecodesign, a Sustentabilidade, a Economia Solidária e a Dialogicidade.

Palavras Chave: Ecodesign; Sustentabilidade; Economia Solidária.

\begin{abstract}
This article presents the trajectory of the University Extension Project Labsol of Solidarity Design, of the Design Department of the Faculty of Architecture, Arts and Communication of the Paulista Júlio de Mesquita Filho State University, on the campus of Bauru. Labsol works in the area of Social Design, relating a perspective that acts on the relationship between design and craftsmanship, through the provision, in a dialogical relationship, to communities producing handicrafts, with the objective of generating work and income, developing products with the intention of recovering cultural identity of the groups served, valuing the local culture and the different ways of doing. Labsol is organized in 2007 on the initiative of the coordinating teacher and a group of volunteer students and in the following years adopts theoretical assumptions that cover Ecodesign, Sustainability, Solidarity Economy and Dialogicity.
\end{abstract}

Keywords:Ecodesign; Sustainability; Solidarity Economy 


\section{Introdução}

O projeto de extensão universitária Laboratório de Design Solidário - Labsol, pertence ao Departamento de Design da Faculdade de Arquitetura, Artes e Comunicação da Universidade Estadual Paulista Júlio de Mesquita Filho, no campus de Bauru, interior de São Paulo e iniciou sua atuação em 2007, por iniciativa do Prof. Dr. Claudio Roberto y Goya. O projeto desenvolve um interessante trabalho, aliando os conhecimentos do Design à produção artesanal, desenvolvendo novos produtos que reflitam aspectos identitários, sociais, históricos e culturais de cada grupo ou comunidade produtora de artesanato atendidos em diversas regiões do Brasil.

O Labsol surgiu em 2007, após a visita do referido professor a uma feira de caridade, no município de Bauru. Na ocasião, ele encontrou a venda tapetes confeccionados por tiras de tecido amarrados uma a uma, sobre um tecido rústico de juta, conhecidos como "tapetes de nozinho", um processo bastante lento e trabalhoso que era vendido ao preço ínfimo de cinco reais. Indignado com o fato de um trabalho humano ser tão insuficientemente valorado, resolveu que a Universidade, mais especificamente a área de conhecimento do Design, poderia contribuir para melhorar essas condições. Convidou primeiramente um aluno, que convidou outros colegas e juntos voluntariamente foram visitar a instituição responsável pela confecção e venda dos tapetes.

A Instituição Beneficente Cristã abriga pessoas com transtornos mentais diversos, que mesmo após o processo de desinstitucionalização dos tratamentos psiquiátricos, não possuíam mais referência ou contato com suas famílias, ou seja, não teriam para onde ir. $O$ trabalho consistia em técnica de terapia ocupacional e os pequenos ganhos serviam para o custeio de algumas necessidades imediatas. Após se inteirar do processo de produção, verificou-se a prevalência de esforços repetitivos, cada interno se atinha a apenas uma tarefa, além de outros elementos que interferiam na qualidade do produto final.

O grupo sugeriu inicialmente que os retalhos fossem organizados por cores, e que os trabalhadores pudessem escolher com que cores pudessem trabalhar, que o forro feito de retalhos fosse retirado do produto e que se criassem linhas sobre o forro de juta para guiar a amarração dos retalhos de malha, além do rodízio nas diferentes atividades de confeç̧ão dos tapetes. Somente estas pequenas alterações que conferiram aos tapetes melhor acabamento e uma palheta mais definida de cores, possibilitaram a sua comercialização por valores que a princípio quadriplicaram seu valor de venda. A partir disto, o grupo se propôs a criar novos objetos a partir dos tapetes: almofadas, poltrona, puff entre outros, procurando criar outros tipos de tarefas, além das de cortar e amarrar retalhos, foi criado um "toy art" juntando à base de tapete pequenas peças costuradas e bordadas, construindo uma peça que usava um quarto de área de um tapete original e era comercializado ao valor de 15 reais, lembrando que o tapete era inicialmente comercializado a 5 reais. (Figura 1) 
Figura 1 - Usuária do Associação Beneficente Cristã, Toys criados a partir da intervenção do Labsol, Cadeira D. Maria I e puff em exposição na Reitoria Unesp em São Paulo.

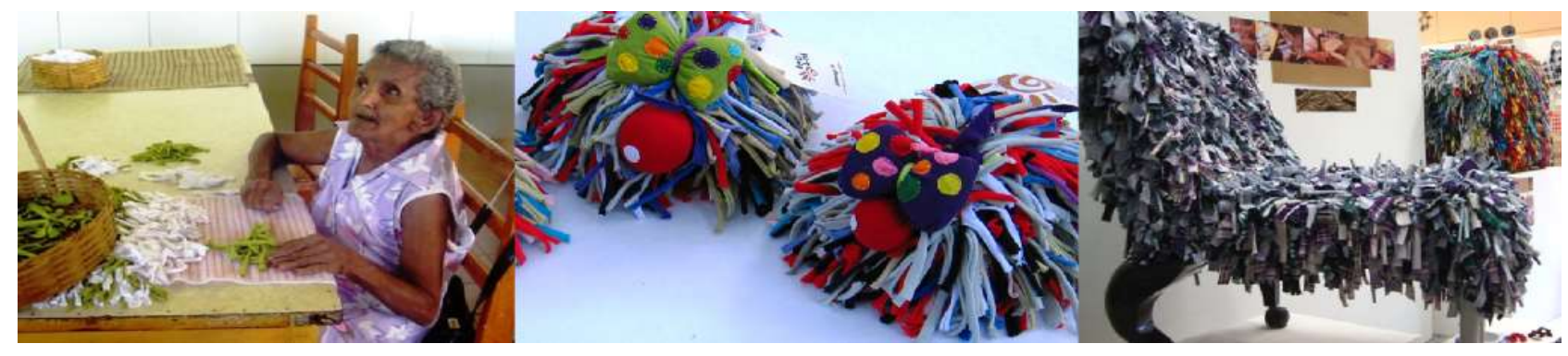

Fonte: Acervo Labsol

A experiência bem sucedida incentivou o recém formado grupo a se lançar a outros trabalhos, tendo como norte levar o conhecimento do design à parcela da população que não o acessa. O fato desta ação ter aparecido na mídia local e seus resultados apresentados em um evento científico levaram novos grupos produtores de artesanato a entrar em contato com a Universidade.

Novas ações foram surgindo e o grupo foi se consolidando com a chegada de novos alunos. Esse novo panorama faz surgir a necessidade de se institucionalizar, baseando-se a princípio em projetos similares, como por exemplo, o projeto Design Solidário, realizado por A CASA, Museu Virtual de Artes e Artefatos Brasileiros, em parceria com diversas entidades, entre as quais a Design Academy Eindhoven, (BASTIAN, 2001).

Com o registro do projeto na Pró-reitoria de Extensão Universitária da Unesp, trabalhando agora com bolsistas e voluntários e demandas surgindo, era o momento de construir a identidade, metodologia e os princípios teóricos que o norteariam, apoiado sobretudo pela aproximação da Rede Universitária de Incubadoras Tecnológicas de Cooperativas Populares como laboratório associado, resultou na imersão e na profunda pesquisa bibliográfica que resultaram na eleição de seus pilares conceituais: o Ecodesign, a Sustentabilidade e a Economia Solidária e principalmente o pensamento de Paulo Freire no que toca ao relacionamento com os grupos de artesãos. Uma vez que se considerou que o que se estabelecia era uma troca de saberes, o artesão detinha um saber e o Design, um outro tipo. Quando eles se somassem, ou se trocassem, constituiriam uma nova plataforma de conhecimento.

Decidiu-se ainda que a demanda seria espontânea, ou seja, os grupos deveriam procurar o LabSol e não o contrário, pois pelos princípios da economia solidária é fundamental respeitar a autonomia dos grupos e não se interpor, não sugerir ao grupo que ele precisa melhorar seu processo sem que ele, por si só, perceba essa necessidade.

O projeto, prestes a completar dez anos de existência, perdura graças a escolha acertada na condução das demandas e da participação dos alunos. Passaram pelo LabSol dezenas de graduandos dos cursos de Design, Relações Públicas e Engenharia de Produção, que foram trazendo seu frescor, aprendendo e ensinando, numa experiência descrita pelos participantes do projeto invariavelmente como única e inestimável. Foram centenas de produtos criados em parceria com dezenas de grupos e comunidades atendidas.

Com o decorrer do tempo verificou-se a necessidade do registro das atividades, principalmente para a memória do projeto e para que os novos participantes se inteirassem das 
reflexões e dos trabalhos já realizados, assim a produção acadêmica do projeto se inicia e se sistematiza, por meio de artigos apresentados em congressos, periódicos e capítulos de livros, na importante divulgação dos resultados para comunidade acadêmica além de proferir palestras de divulgação cultural, função intrínseca da universidade, que por sua vez tem fomentado a procura por parte das comunidades, reavivando a possibilidade de disseminar a contribuição por uma sociedade socialmente justa e ambientalmente correta.

\section{Embasamento}

Com o passar dos anos o Labsol desenvolveu sua reflexão teórica, apoiando-se em bases conceituais que referenciam seu trabalho e serão apresentados na sequência: A Sustentabilidade, o Ecodesign, o Design Social, a Economia Solidária e a Dialogicidade que o guia no relacionamento com os grupos atendidos.

\subsection{Sustentabilidade}

Segundo Manzini \& Vezzoli (2008), sustentabilidade faz referência às condições sistêmicas, segundo as quais em nível regional e planetário, as atividades humanas não devem interferir nos ciclos naturais em que se baseia tudo o que a resiliência do planeta permite, e ao mesmo tempo, não devem empobrecer seu capital natural, que será transmitido às gerações futuras.

O desenvolvimento sustentável é aquele que atende às necessidades do presente sem comprometer a possibilidade de as gerações futuras atenderem a suas próprias necessidades. Essa preocupação tornou-se frequente nas últimas décadas, repercutindo mundialmente, principalmente entre os países mais industrializados. (Comissão Mundial sobre Meio Ambiente e Desenvolvimento - CMMAD 1988).

Entende-se, portanto, que sustentabilidade é a capacidade de determinado grupo, de manter-se em um meio evitando acarretar estes impactos e perturbações graves. Na proposta organizacional humana, que haja harmonia na convivência entre a natureza e o homem, obstando danos à biodiversidade e ecossistemas locais e planetários.

\subsection{Ecodesign}

Ecodesign é o termo para a tendência, em que o objetivo principal é projetar lugares, produtos e serviços que, de alguma forma reduzam o uso de recursos não renováveis ou minimizem o impacto ambiental, e tem sido visto como uma ferramenta necessária para que algum dia se alcance o desenvolvimento sustentável.

Para Manzini e Vezzoli (2008), o ecodesign consiste no estudo e na análise dos recursos renováveis e não renováveis, além dos resíduos gerados, com a finalidade de criar formas de aplicação na produção de novos produtos. Pretende-se ampliar a vida útil desses dos recursos, minimizando o impacto ao meio ambiente.

Explicitam ainda que Ecodesign é "uma aptidão projetual, que concebe os aspectos do projeto, considerando também o impacto ambiental" (Manzini e Vezzoli, 2008, p. 18), e "considera-se o produto desde a extração dos recursos necessários para a produção dos materiais que o compõem (nascimento) até o último tratamento (morte) desses materiais após o uso do produto". (Manzini \& Vezzoli, 2008, p. 91) 
É possível encontrar relação entre o Ecodesign e o Life Cycle Design (Ciclo de Vida do Produto), que por sua vez compreende a busca pela redução dos "inputs" e "outputs" durante o ciclo de vida de determinado material ou produto, promovendo modificações nos processos de fabricação e desenvolvimento dos mesmos, reduzindo os impactos ambientais por eles causados. Esse declínio ocorre devido a fatores decididos durante a pré-produção, produção, distribuição, uso, reutilização e descarte do produto. Adentrando ao contexto do ciclo de vida, considera-se a possibilidade de reciclagem e/ou reutilização de seus materiais e/ou componentes, promovendo um acréscimo de tempo na vida útil dos materiais e produtos já produzidos.

\subsection{Design Social}

As bases do Design Social foram fundadas por Papanek (1977) quando afirma que os designers tem a responsabilidade e a possibilidade de fazer mudanças no mundo através do Design, e que o Design deveria se preocupar com as necessidades humanas e sociais avançando sobre o pensamento Ulmiano do Design a serviço da sociedade de consumo. Assim, o Design Social é uma abordagem de projeto que enfatiza as motivações e consequências sociais do processo de Design e tem como objetivo desviar o foco do Design no produto na elite econômica e no consumismo, promovendo o desenvolvimento social.

\subsection{Economia Solidária}

Economia Solidária tem em sua base a subversão da lógica capitalista e toda a formação da sociedade que sua prática engendra. Do modo de produção capitalista, deriva-se a competitividade e a prevalência do capital, em detrimento do ser humano. Singer (2002) elucida os efeitos da competição, muitas vezes escondidos, que são os perdedores da constante competição e as consequentes e crescentes desigualdades sociais decorrentes. Para que a economia não seja mais produtora de desigualdades é necessário cessar a competição e iniciar a solidariedade.

Assim sendo, Singer define que a Economia Solidária:

A economia solidária é outro modo de produção, cujos princípios básicos são a propriedade coletiva ou associada do capital e o direito à liberdade individual. A aplicação desses princípios une todos os que produzem numa única classe de trabalhadores que são possuidores de capital por igual em cada cooperativa ou sociedade econômica. (SINGER, 2002, p.10).

Dentro desse meio, as decisões são tomadas em conjunto buscando o benefício mútuo, pois são fundamentadas nos conceitos de cooperação, preservação dos recursos naturais e igualdade de poder na tomada de decisões e consequente responsabilidade para com a comunidade local onde o empreendimento está inserido.

\subsection{Dialogicidade}

A Dialogicidade é um dos principais pressupostos em que se base a teoria freiriana. 0 diálogo nasce na prática da liberdade, enraizado na existência, comprometido com a vida, que se historiciza no seu contexto. Seu oposto seria a educação bancária, aquela onde inexiste o diálogo e 
as informações são depositadas no individuo, constituindo assim prática antialógica, como explica no seu livro Pedagogia do Oprimido (FREIRE, 1987).

Pode-se definir que a dialogicidade é a essência da educação como prática da liberdade. 0 diálogo é tratado como um fenômeno humano em Paulo Freire,

[...] se nos revela como algo que já poderemos dizer ser ele mesmo: a palavra. Mas, ao encontrarmos a palavra, na análise do diálogo, como algo mais que um meio para que ele se faça, se nos impõe buscar, também seus elementos constitutivos (FREIRE, 1987, p.89).

Não há palavra que não seja práxis, ou que não surja da práxis, quando pronunciamos a palavra, estamos pronunciando e transformando o mundo. Na dialogicidade estão sempre presentes as dimensões da ação e da reflexão. Ao pronunciar o mundo mostramos que humanamente existimos, se existimos, agimos e modificamos o mundo dado. Quando não há verdadeiro diálogo, não há encontro, amorosidade e respeito.

Podemos sintetizar isso expondo que:

O diálogo é este encontro dos homens, imediatizados pelo mundo, para pronunciá-lo, não se esgotando, portanto, na relação eu-tu. Esta é a razão por que não é possível o diálogo entre os que querem a pronúncia do mundo e os que não querem; entre os que negam aos demais o direito de dizer a palavra e os que se acham negados deste direito (FREIRE, 1987, p. 91).

Daí que concluímos que o diálogo é uma exigência existencial, é encontro.

\section{Metodologia}

\subsection{Metodologia de abordagem aos grupos e comunidades}

Os trabalhos realizados pelo Labsol são empíricos e de caráter prático. O projeto contém um conjunto de ações contínuas e sistematizadas de caráter educativo, cultural, político, científico ou tecnológico, desenvolvidas junto a outros setores da sociedade, que não está dentro da universidade.

O primeiro contato costuma ser realizado pela própria comunidade, partindo do princípio que é ela quem identifica a sua própria demanda e decide que precisa de assessoria técnica. Também ocorre de entidades ligadas a ela intermediarem o contato, como instituições de ensino, Incubadoras Tecnológicas de Cooperativas Populares (ITCP's) e órgãos públicos. Em seguida é organizado um programa de visita com os integrantes do laboratório, para que se conheçam os artesãos, sua realidade, materiais, técnicas e métodos de trabalho e ocorre um workshop para que os integrantes do laboratório aprendam com o grupo. De volta ao laboratório, são realizados os primeiros estudos, os quais são submetidos à comunidade, e, caso ela esteja de acordo, são desenvolvidos projetos, produzem-se modelos e protótipos, até obter-se os produtos finais.

Antes da apresentação dos resultados às comunidades, são realizadas feiras para a comercialização dos artefatos. Estas possibilitam a análise da aceitação de mercado, visando testar outros produtos elaborados e aumentar a visibilidade do projeto. Há uma ressalva no que se refere ao desenvolvimento do projeto, sendo este um caminho de mão dupla, onde há uma troca de saberes a todo tempo. Dessa forma, projeto envolve a participação efetiva da população externa como sujeitos ativos no processo, sem, evidentemente, excluir a participação da 
população externa. O desenvolvimento dos novos produtos, a partir das demandas dos grupos atendidos é tido como uma retribuição do Labsol ao conhecimento adquirido durante o processo de trabalho.

\subsection{Metodologia de projeto dos produtos desenvolvidos}

Uma das abordagens está contida na literatura "Metodologia do Projeto em Design do Produto" (BAXTER, 2000). O projeto procura atender as demandas das comunidades atendidas e o desenvolvimento de novos produtos que agreguem valor a produção artesanal das oficinas, tendo em conta as questões socioculturais em que a associação está inserida. A metodologia de projeto em Design é utilizada na reformulação dos produtos já existentes e na criação de novos, adaptando métodos e processos de produção. É importante manter todas as portas abertas para a geração de conceitos, desde que as mesmas sejam formuladas de maneiras realistas, dentro das possibilidades técnicas e econômicas da empresa (BAXTER, 2000, p. 176). No sétimo capítulo, "Projeto conceitual", Baxter destaca que o termo conceito faz parte do processo de criação de uma peça de design. Afirma que a geração de maior número possível de conceitos é o ideal para o sucesso de um projeto conceitual para que o melhor seja selecionado. Baxter propõe que o processo de desenvolvimento de produto bem como o objetivo necessita passar por etapas de observação de percepção do "problema", considerando os aspectos visuais, de fabricação e técnicas utilizadas, as demandas do mercado, preocupação ecológica e com o custo envolvido, além da satisfação do consumidor.

\section{Trabalhos desenvolvidos}

\subsection{Escola de Samba Coroa Imperial}

Em 2013, o Labsol foi convidado a compor uma parceria com o projeto NeoCriativa Núcleo de Estudos e Observação em Economia Criativa, a trabalhar no desfile de Carnaval Coroa Imperial 2014. A ideia foi, através da parceria com os projetos de extensão da Unesp, promover e incentivar essa manifestação cultural e artística, colocando a comunidade local em contato com a Universidade.

Fundado em 1992, o Grêmio Recreativo Escola de Samba Coroa Imperial da Grande Cidade é uma escola de samba movida por um grupo familiar tradicional do bairro Núcleo Residencial Presidente Geisel em Bauru, São Paulo passava no momento por sérias dificuldades estruturais e financeiras, procurando o Labsol sabendo que este trabalhava com materiais recicláveis.

Ao deparar-se com a grande quantidade de materiais e fantasias usadas em outros carnavais no depósito da Coroa Imperial e aplicando os conceitos que norteiam o Labsol de maneira efetiva, passou-se a reciclar materiais e fantasias que se encontravam no barracão, desenvolvendo junto à Escola de Samba uma nova mentalidade a respeito de reaproveitamento.

O enredo foi escolhido no início do mês de setembro e coube aos participantes do projeto junto a comunidade criar as fantasias e alegorias para o desfile. Em outubro de 2013, todos os protótipos haviam sido entregues, com seus respectivos moldes e fichas técnicas.

Após o recesso acadêmico, o Projeto voltou a procurar a escola para avaliar o andamento da confecção das fantasias e o trabalho ainda não havia sido iniciado, faltando pouco mais de um mês para o carnaval. A partir dessa constatação, o que poderia ser feito, senão acompanhar de perto a confecção das fantasias? Em meio às dificuldades encontradas, pode-se superar o 
envolvimento que o projeto já prevê com as comunidades atendidas. A troca de conhecimentos se intensificou e foi possível aos alunos conhecer ainda mais de perto outra realidade. A convivência passou a ser diária, criando laços entre as pessoas da comunidade. Compreendeu-se então que o conhecimento popular se difunde a partir do fazer e não pelas linguagens eruditas de projeto, prática que o Labsol sempre havia adotado em outros grupos, mas que até aquele momento não havia se dado conta. A Escola de Samba última colocada no desfile anterior obteve um honroso terceiro lugar (Figura 2).

Figura 2 - Carnaval de 2014. Mestre sala e porta-bandeira, comunidade participando da confecção das fantasias de ala, comissão de frente onde foram utilizadas radiografias filetadas no lugar de plumas.

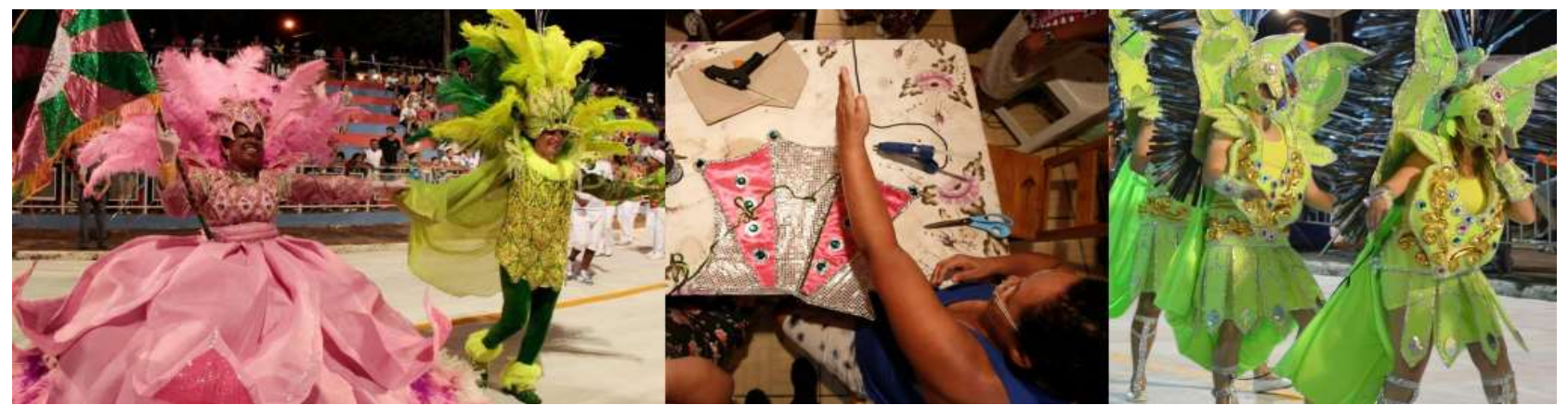

Fonte: Arquivo Labsol

Em 2015 o enredo escolhido foi "Quem não dança segura a criança" onde foi possível abordar a dança especialmente pelo seu aspecto cultural e assim representar várias regiões do Brasil. A escolha não foi ao acaso, ela levou em conta os materiais que seriam reaproveitados do desfile de 2014. Foi adotado o uso da chita, material colorido e de baixo custo e que coadunava com o tema escolhido. Outro aspecto importante foi a adoção de fantasias volumosas, de modo a tornar a escola mais compacta e aparentemente maior (Figura 3). Essa decisão foi acertada e resultou no prêmio "Tamborim de Ouro" na categoria "Evolução", conferido pelo programa de televisão especialista em Carnaval de Bauru - o "Casa de Bamba".

Figura 3 - Carnaval de 2015. Ala Folia de Reis, Comissão de Frente, Carro alegórico “Boi Bumbá.

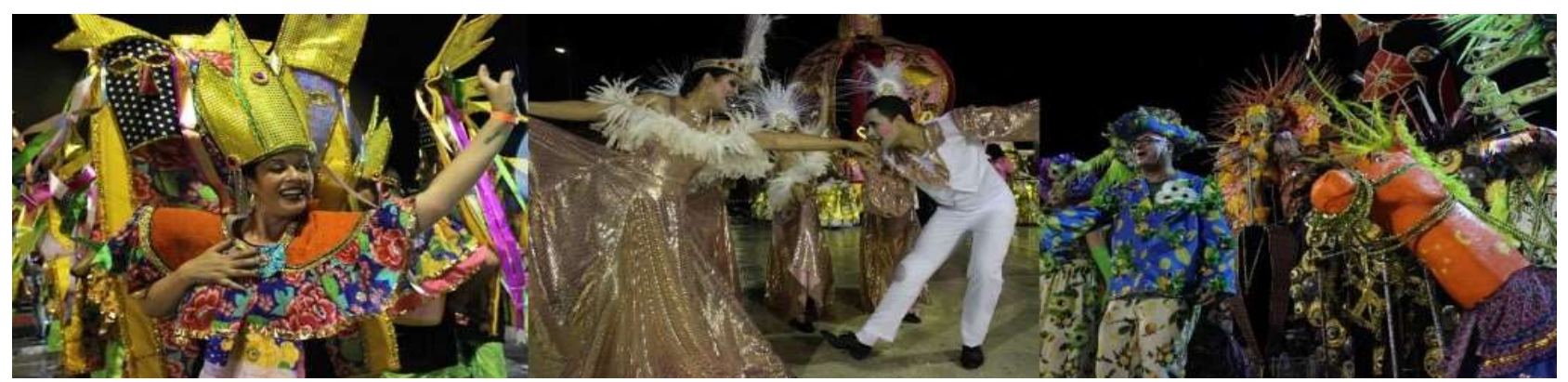

Fonte: Arquivo Labsol

O enredo escolhido para o desfile de 2016 procurou representar a América Latina e recebeu o nome "América Mestiça. Mãe, Terra", a proposta levava em conta o aproveitamento máximo de materiais usados no desfile do carnaval anterior. Com dez alas e quatro carros 
alegóricos foi contada um pouco da história da formação da América Latina e de suas distintas regiões etnogeográficas (Figura 4).

Esse desfile corou de êxito a parceria, com notas altas dos jurados e o honroso terceiro lugar, atrás por meio ponto apenas, de uma das maiores escolas da cidade. Além disso, a escola recebeu mais três prêmios, o "Tamborim de Ouro" de melhor fantasia de ala: os "Portugueses", melhor samba-enredo e melhor harmonia.

O resultado que o projeto comemora foi sua relação mais intensa com uma comunidade e o aprendizado dos alunos, que puderam fazer uso de materiais e técnicas distintas, próprias do carnaval. A Coroa Imperial encontrou na Universidade um caminho para desenvolver seu Carnaval, o que propiciou uma troca mútua de conhecimentos, técnicas e habilidades dos processos criativos. Entre outros frutos, a parceria proporciona a formação dos alunos para além da sala de aula, com espaço para o desenvolvimento das questões sociais e políticas, cumprindo assim com um dos mais importantes papeis da Universidade Pública.

Figura 4 - Carnaval de 2016 - Mestre sala e porta-bandeira, ala de passo marcado, destaque do carro alegórico "Barroco".

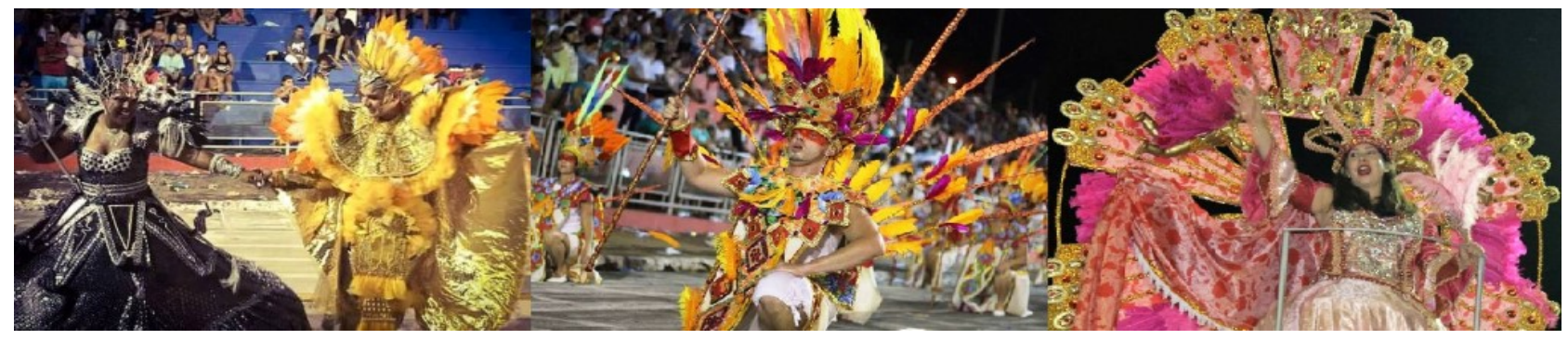

Fonte: Arquivo

\subsection{Escola de Samba Cartola}

A parceria teve início ainda no ano de 2016 , no mês de outubro, quando o LABSOL foi procurado, em função da notoriedade da parceria que durou três anos, com o Grêmio Recreativo Escola de Samba "Coroa Imperial da Grande Cidade". O Laboratório solicitou a oportunidade de continuar a desenvolver um trabalho pautado no reaproveitamento de materiais advindos de fantasias criadas para outros desfiles, a fim de praticar e difundir a sustentabilidade no carnaval. Partes acertadas e de comum acordo, havia muito trabalho a ser cumprido em um curto período de tempo. O carnaval sofria com a insegurança da mudança de gestão na Prefeitura do Município de Bauru, que tardou em garantir que a verba destinada às escolas de samba anualmente seria liberada.

O enredo escolhido foi resultado da troca de conhecimentos entre o saber acadêmicos e o popular. A ideia foi de uma das responsáveis pela execução das fantasias da Coroa Imperial, Michele de Oliveira. "Felizes para sempre no reino encantado na Cartola" remontou os principais e mais conhecidos contos de fadas, transmitidos pela tradição oral, de geração em geração. Foram prototipadas 10 alas, sendo 5 a partir de fantasias de outros desfiles e as outras utilizando materiais que a escola já possuía, mas não havia conseguido encontrar utilidade. Um exemplo 
interessante foi a incorporação de resíduos de um plástico bolha azul que é comercializado com a finalidade de cobrir piscinas à uma fantasia de ala, o Gato de Botas. Além das alas, foram idealizados 4 carros alegóricos e elaborados 60 destaques, entre comissão de frente, mestre sala e porta-bandeira, rainha de bateria, destaques de chão e de carro alegórico, totalizando 74 produtos técnicos elaborados, sempre preconizando o reaproveitamento, técnica que atende aos princípios do Ecodesign e da Sustentabilidade, ambos, pilares conceituais do LABSOL.

Figura 5 - Carnaval de 2017 - Ala Doce Tentação, ala da Magia, ala Lobo Mau - bateria

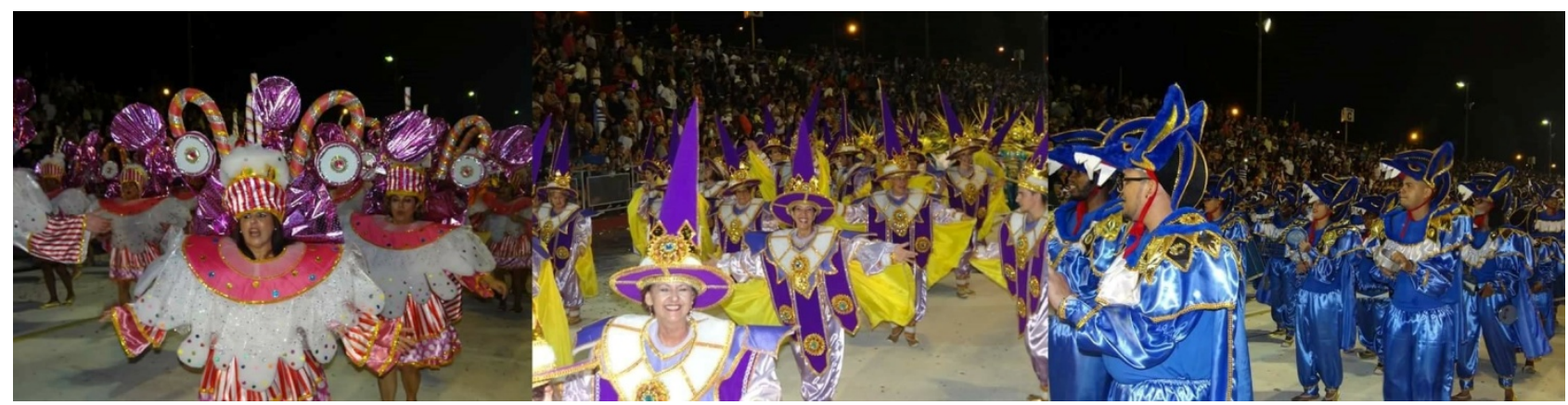

Fonte: Acervo Labsol

O trabalho obteve várias formas de êxito, entre eles um honroso segundo lugar na classificação geral do carnaval, entre as escolas de samba do município de Bauru. Contudo, o LABSOL considera que outras conquistas foram mais importantes, do ponto de vista sociocultural e científico, como a valorização da cultura por meio da arte das comunidades, expressa no carnaval, o fomento da criação de uma consciência da importância da sustentabilidade ambiental e o aprendizado dos alunos sobre a utilização de novos materiais, técnicas, processos, bem como a construção de conhecimentos pautados na prática, na relação com a comunidade da escola de samba, num ambiente profícuo à formação para a cidadania.

Outro resultado importante foi a redução de custos que o carnaval sustentável gerou. 0 presidente da escola declarou ao Jornal da Cidade, na edição do dia 27 de fevereiro de 2017: "Este foi um dos Carnavais mais baratos da Cartola, porém, um dos melhores". O trabalho a partir desta parceria proporciona a difusão da existência de um projeto de extensão atuante, como é o LABSOL, para o município de Bauru e região, para a UNESP e outras universidades, por meio de reportagens nos meios de comunicação e pelo desenvolvimento de pesquisas.

No ano de 2017 a parceria continuou, na preparação para o carnaval que foi apresentado em 2018. Desta vez com o enredo "As mãos", escolhido pelo presidente da agremiação. A premissa era representar no desfile tudo o que as mãos são capazes de fazer, como trabalhar, criar, curar, brincar, plantar rezar e fazer o carnaval. Neste ano a escola dispunha de menos recursos financeiros e realizou um trabalho mais modesto, principalmente com os carros alegóricos. Para que isso se concretizasse se fez mister o reaproveitamento de elementos de 
desfiles anteriores. A escola de samba e o Labsol foram coroados de êxito, alçando o primeiro lugar entre as escolas de samba da cidade Bauru, que foi muito festejado por toda a comunidade.

Figura 6 - Desfile de 2018, fantasia de ala "As mãos que rezam - São Jorge", Carro alegórico

"As mãos que criam - o artesanato", fantasia de ala "As mãos de que colhem - A festa da colheita"

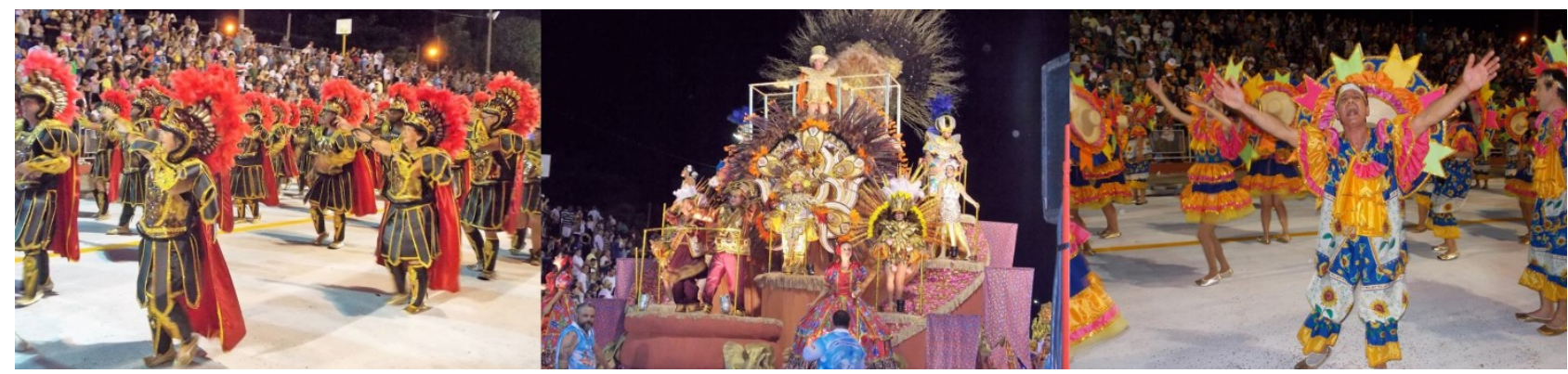

Fonte: Acervo Labsol

\subsection{Associação dos Artesãos de Pompeia e Jacto}

O convite partiu de um designer graduado pela UNESP Bauru, Anderson Rolim, que integra a equipe da JACTO, indústria máquinas agrícolas da cidade de Pompeia, SP, no sentido de cumprir com sua responsabilidade social, a JACTO possui uma parceria com a Associação dos Artesãos de Pompeia - AAP. O designer procurou o LABSOL com a proposta de buscar aprimorar e aplicar técnicas de design aos produtos existentes e criar outros a partir de novos materiais e ideias. $\mathrm{Na}$ visita inicial houve a apresentação da associação e seus membros e o reconhecimento das peças artesanais produzidas.

Notou-se que os artesãos possuíam grande habilidade com costura, entretanto os objetos produzidos não ofereciam grande potencial mercadológico, por não se diferenciarem nem denotarem a identidade cultural da cidade ou mesmo dos próprios artesãos. Em seguida, foi realizada uma reunião de brainstorm entre os parceiros. Entre as sugestões propostas, a escolhida para uma coleção a ser elaborada conjuntamente foi a de artefatos a partir da reutilização de lonas vinílicas, material encontrada em abundância na JACTO.

Figura 7 - Reunião com a AAP e com a Jacto, Cachepot confeccionado a partir de lona vinílica

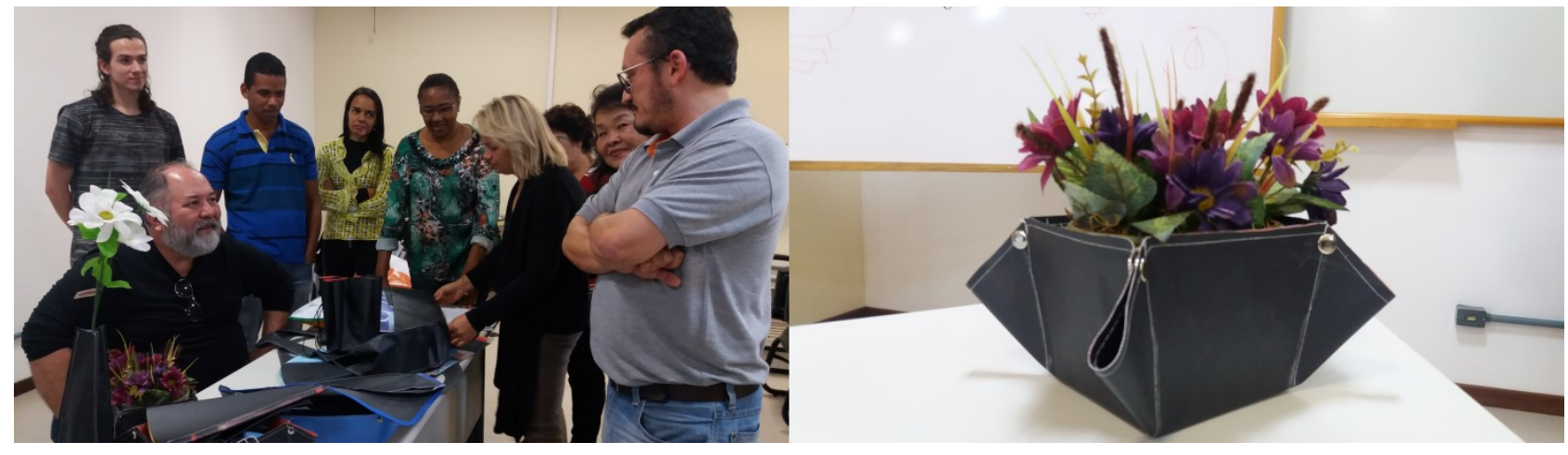

Fonte: Acervo Labsol 
O LABSOL desenvolveu 17 protótipos, entre bolsas, vasos, cachepôs, jogos americanos, porta-pães, estojo de ferramentas, entre outros. As criações foram recebidas com entusiasmo na visita devolutiva. No mês de novembro, o LABSOL intermediou a inscrição da AAP em uma feira que ocorreu durante o 13을 Colóquio de Moda, que foi sediado pela UNESP Bauru. A participação serviu para testar o potencial de vendas dos novos artefatos. Esta foi apenas a primeira etapa desta até então bem sucedida parceria tripartite.

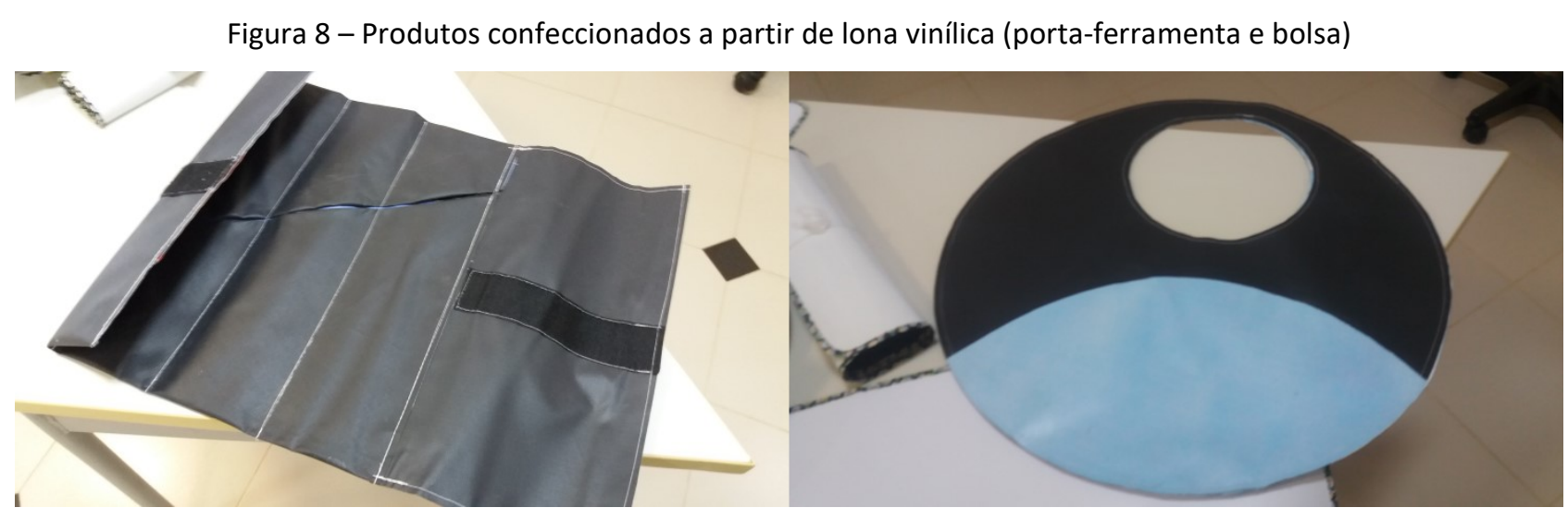

Fonte: Acervo Labsol

\subsection{Oficina LABSTAMPE e Instalação}

Com a finalidade de divulgar o projeto entre os estudantes de design, o LABSOL decidiu realizar a oficina LAB STAMPE, em parceria com o projeto de extensão LABDESIGN, também da FAAC. A ação contou com três etapas, a primeira consistiu na exposição de camisetas usadas doadas por uma empresa e varais, na praça dos blocos de salas de aula destinadas ao curso de Design, da FAAC, procurando suscitar impacto e curiosidade, já que não havia sido divulgada ainda que seria proposta uma oficina.

Na segunda etapa, os alunos foram convidados a estampar as camisetas e a instalação foi desmontada. Os inscritos tinham à sua disposição diversas telas de silk, algumas confeccionadas especialmente para a ação, e poderiam criar livremente as estampas de uma ou mais camisetas, que seriam doadas a eles. Na terceira etapa, foram instalados varais novamente, mas dessa vez com as estampas dos alunos, com o intuito de provocar reações nos alunos que não participaram da segunda etapa.

A realização desta oficina teve alguns propósitos, como demonstrar a necessidade de se pensar o consumo de forma consciente, oportunizar o contato com a técnica de estamparia a base de silk e também de divulgar o LABSOL enquanto projeto de extensão universitária. É importante salientar a preocupação da empresa, ao procurar o LABSOL, projeto que se compromete com prolongamento da vida útil da matéria-prima, neste caso, contida na camiseta. 
Figura 9 - Instalação de camisetas a serem reutilizadas

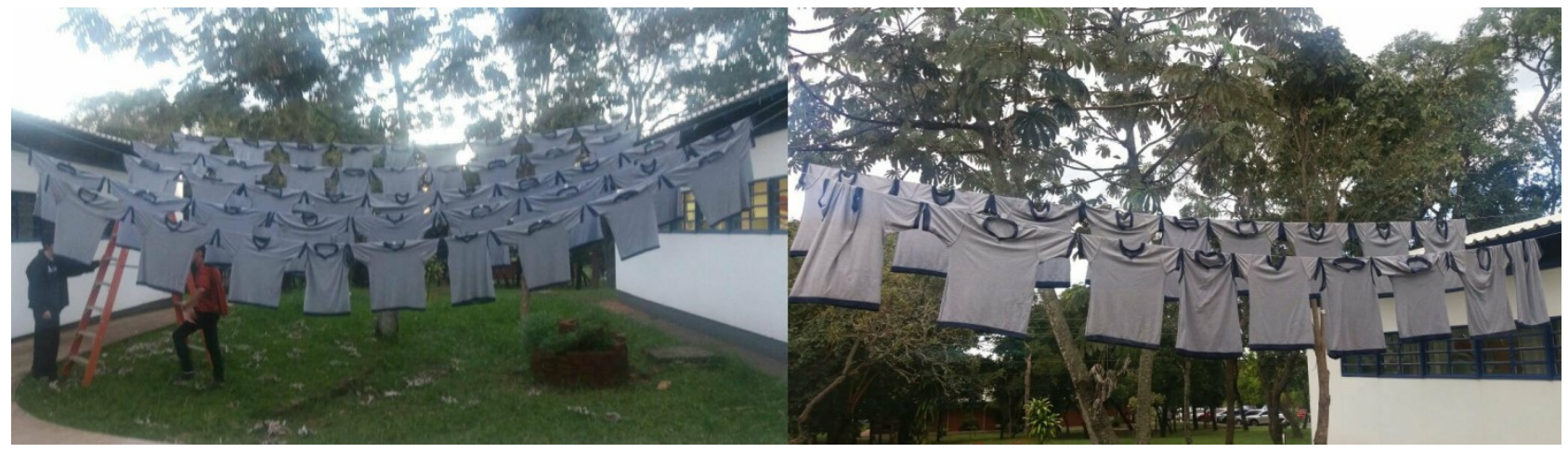

Fonte: Acervo Labsol

\section{Considerações Finais}

O projeto Labsol tem proporcionado aos alunos experiências que só a extensão universitária proporciona. O contato indelével com universos distintos, por meio da convivência com as comunidades, em especial com a comunidade da Coroa Imperial da Grande Cidade, por sua intensidade, forja o caráter e proporciona a oportunidade de promover ações que não se encerram na simples transmissão dos conhecimentos produzidos na universidade, mas se pautam no processo dialógico, onde acontece a troca de saberes. $O$ saber popular, aliado ao conhecimento erudito, formarão um novo saber, que por meio da verificação da realidade se torna efetivo. 0 saber, produto dessa relação é então, passível de promover mudanças sociais reais e não apenas elucubrações que ficam apenas dentro dos muros da universidade. $O$ aluno que tem a oportunidade de, durante a sua graduação, experenciar o Labsol, não se forma apenas como designer, se forma também como cidadão cônscio dos seus deveres para com a sociedade.

\section{REFERÊNCIAS}

BIRKELAND, J. Design for sustainability: a sourcebook of integrated, ecological solutions. London: Stearling, 2002.

BASTIAN, Winnie. Design holandês e artesanato brasileiro. Publicado por A CASA em 29 de Novembro de 2001. Disponível na internet por http em: <http://www.acasa.org.br/biblioteca/texto/90> Acesso em 15 mai. 2016.

BORGES, Adélia. Design+Artesanato. São Paulo: Terceiro Nome, 2011.

BREZET, H. VAN HEMEL, C. BÖTTCHER, H. CLARKE, R. Ecodesign: a promising approach to sustainable production and consumption: UNEP, 1997.

CAVALCANTI ,Claudia. ARTESANATO, produção e mercado. Uma via de mão dupla. São Paulo: Central ArteSol, 2002.

DESIGN POSSÍVEL. Quem Somos. Disponível em na internet por http em: <http://www.designpossivel.org/sitedp/sobre-2/quem-somos/>. Acesso em 11 de mai. 2016.

FREIRE, Paulo. Pedagogia do oprimido. 17ạ edição, Paz e Terra, Rio de Janeiro, 1987.

Educação como prática da liberdade. Rio de Janeiro, Paz e Terra, 2007. 
FREITAS, Ana Luiza Cerqueira de. Design e artesanato: uma experiência de inserção da metodologia de projeto de produto. São Paulo: Blucher Acadêmico, 2011.

GOYA, C. R., Carnaval, Cultura Popular e Design - Uma Experiência de Extensão Universitária em Design In: Ensaios em Design - Práticas Interdisciplinares.1 ed. Bauru: Canal 6 Editora, 2014, p. 136-156.

MANZINI, E.; VEZZOLI, C. O Desenvolvimento de Produtos Sustentáveis. São Paulo: USP. 2008.

PAPANEKI, Victor J. Diseñar para el mundo real. Madrid: Editora Blume: 1977.

SINGER, Paul. Introdução à Economia Solidária. São Paulo: Fundação Perseu Abramo, 2002. 